\title{
EKC HYPOTHESIS AND THE EFFECT OF INNOVATION: A PANEL DATA ANALYSIS
}

\section{DOI: 10.17261/Pressacademia.201519952}

\author{
Billur ENGIN BALIN ${ }^{1}, \mathrm{H}$. Dilara MUMCU AKAN ${ }^{2}$ \\ ${ }^{1}$ Istanbul University, Turkey. E-mail: b.engin@istanbul.edu.tr \\ 2 Istanbul University, Turkey. E-mail: dimumcu@istanbul.edu.tr
}

\begin{tabular}{ll}
\hline Keywords: & ABSTRACT \\
Environmental Kuznets Curve, & $\begin{array}{l}\text { In recent years, sustainable development has represented } \\
\text { one of the most important aims of the economic policy } \\
\text { Innovation, }\end{array}$ \\
explored in the environmental Kuznets curve (EKC) \\
CO2 emissions & $\begin{array}{l}\text { literature. The present paper contributes to this ongoing } \\
\text { literature by comparing two different EKC specifications } \\
\text { for } 27 \text { developed countries over the period 1997-2009 }\end{array}$ \\
JEL Classification: & using panel data methods. It is found an N-shaped \\
Q56, Q55, Q54, C23 & relationship between CO2 per capita and GDP per capita \\
& which differs from the traditional U-shaped EKC. The \\
paper also examines the possible effects of innovative & investments and industrial production on the \\
environmental Kuznets curve (EKC) for CO2 emissions.
\end{tabular}

\section{INTRODUCTION}

The sustainability and environmental effects of economic growth have been examined remarkably since 1970's. In the renowned report of Rome Club "The Limits of Growth" (Meadows et al., 1972); the increasing economic activity on the one hand requires more input and on the other hand creates more waste and here at it is argued that environmental quality would be decreased. This negative externality spread to the environment, especially would ruin the nonrenewable natural resource stock and after all threaten the economic activity herself. Accordingly, the Rome Club was referring that only if the economic growth is limited today the growth hereafter will proceed.

The doomy view of 70's, from 90's onwards was replaced with theoretic and empirical studies investigating the environmental effects of economic growth by linking the stages of development. The common of these studies are: at the early stages of development as economic growth increases the environment is more ruined solely in the proceeding stages of development the situation reverses. With the simplest definition Environmental Kuznets Curve Hypothesis ${ }^{1}$ brings forward an inverted $U$ shape relationship with income per capita and environmental damage. The hypothesis takes its footing from Simon Kuznets Nobel laureated study fulfilled in 1955 titled as "Economic Growth and Income

\footnotetext{
${ }^{1}$ As the issue in environmental economics literature is examined under the heading of "Environmental Kuznets Curve" in the residual part of this study the original abbreviation of the expression EKC will be used.
} 
Inequality". In this study Kuznets defines the empirical relationship of mentioned variables as an "inverted-U relationship".

Thereby the EKC hypothesis does not consider the environmental degradation as a limit for environmental growth on the contrary claims that growth will resolve at least a part of this problem. Our aim is to investigate (i) whether the EKC relationship is well specified for $\mathrm{CO} 2$ (ii) if there is a significant relationship between $\mathrm{CO} 2$ emissions and innovative investments. Our models are estimated using panel data methods in order to control the heterogeneity and the colinearity among the variables (Baltagi, 2005). The remainder of this paper is organized as follows. Section 2 presents a brief literature review for the EKC Hypothesis. Section 3 describes the models and the source of data samples that is used in the models. Section 4 presents the empirical results of EKC effect of economic growth and innovative investments. Section 5 provides a brief conclusion.

\section{LITERATURE REVIEW}

EKC hypothesis elementarily exposes that environmental destruction is not a constraint for economic growth and supports sustainable development view. This hypothesis has been subject to many theoretical and empirical studies. Among these, three studies which have pioneering qualification can be mentioned as: Grossman and Krueger (1991, 1995), Shafik and Badyopadhyay (1992) and Panayotou (1993) who entitles the topic as EKC, in his studies with a numerous pollutant and gross domestic product there is an inverted $U$ relationship.

Selden and Song (1994) argue that the inverted $U$ shaped relationship between environmental quality and development would be formed with the impact of both demand and supply side influence. As it is viewed from demand side, the validity of EKC hypothesis is relevant with the environmental quality being accepted as luxury good whose income elasticity is greater than unit. (Beckerman, 1992; Carson et al., 1997; Shafik, 1994). Yet as social welfare rises both the individuals are more disposed to use ecofriendly products and the authority is more pressurized for making regulations concerning preservation of environment. With the increasing per capita income the society's clean environment demand only in democratic societies will pressurize governments to perform active environmental policies. Therefore the feature of political system for the validity of EKC hypothesis is an important factor that we confront. (Bhattarai and Hammig , 2001; Shafik and Bandyopadhyay, 1992; Torras and Boyce, 1998).

When examined from supply side, it has been asserted by Grossman and Krueger (1995) that economic growth had an impact on environmental quality in three different channels. According to one of these channels "scale effect", as with the increasing economic activity, ceteris paribus, causes the increasing environmental degradation. Likewise the increasing production activity cause the resource consumption rate to mount on resource renewal ration besides waste production increases both in quantity and toxicity. In pursuit of the effect of scale emergent "composition effect" comprises the structural variations in economy with the increasing production. The significance in production shifted from manufacturing industry to knowledge intensive industries and service sector is an indicator of structural change; hence it can be told that this has environmental deductive effects. 
Finally a rise in society's environmental consciousness both to refrain from the pollution created by environmental policies and an increase in the cost of eco-friendly technologies is entitled as "technological effect". In this context EKC hypothesis asserts, in the first phases of development when per capita income increases effect of scale is dominant; pollution per capita also increases conversely after a certain level of per capita income level due to composition and technological effects and being dominant over effects of scale, this trend will become reversed.

While the EKC hypothesis was being formed for the exigency of the hypothesis the independent variable was per capita income, as dependent variable the per person amounts of certain various pollutants was used. Mostly as a benchmark the usage of GDP per capita and occasionally real GNP can be perceived as a matter open to criticism. Barely in terms of the model's feasibility the components that effect income and development of political structure; education level, the composition of output are tackled and others with respect to the influence on income, and they prevent the model to become confusing.

As for pollutants many types of variables were used, particularly CO (carbon monoxide), CO2 (Carbon dioxide), SO2 (sulfur dioxide) and NOX (nitrogen oxides) items that cause air pollution in the cities are more frequently used as independent variable. Many authors indicate the prime cause of this as the aforementioned variables existence for a long time period. Besides this, at a certain time period and forest zone change criteria as clean water amount per person, the heavy metals and toxic chemicals present in water, the amount of undissolved oxygen for the necessity of organic life in rivers and other criteria have been used concerning environmental quality.

Some extended versions of the EKC have been proposed with the aim of including factors such as technology impacts, energy consumption, energy prices, labor, trade-related factors, environmental regulation or policy, and environmental concerns (Ayres and Van den Bergh, 2005; Dasgupta et al., 2006; Halicioglu, 2009; Lantz and Feng, 2006). Nevertheless few attempts have been made in order to consider the effect of innovation. He and Jiang (2012) compared the two groups of samples, which described energy consumption per unit of industrial added value, each group contains five symbolic provinces or municipalities in coastal and western areas. They found the positive significance effect of the technological innovation. Huang (2011) analyzed the internal relationship between Porter Hypothesis and Environmental Kuznets Curve and concluded that the progress of Porter Hypothesis ${ }^{2}$ also relies on economic growth, which is compatible with EKC. By giving the central role of technological progress in long-term environmental problems, Baiardi (2013) empirically investigated the influence of innovation on the EKC and found that innovation influences the EKC directly and indirectly, given its close relationship with income.

\footnotetext{
${ }^{2}$ Porter hypothesis suggests that strict environmental regulation triggers the innovation and introduction of cleaner technologies and environmental improvements, the innovation effect, making production processes and products more efficient. (Porter and van der Linde, 1995)
} 


\section{DATA SOURCES AND MODELS}

In most of the studies making query for the validity of EKC hypothesis in terms of certain pollutants are based on the reduced model below:

$$
E_{i t}=\beta_{0}+\beta_{1} X_{i t}+\beta_{2} X_{i t}^{2}+\beta_{3} X_{i t}^{3}+\beta_{4} Z_{i t}+e_{i t}
$$

In this equation $E_{i t}$ denotes pollutant amount in region/country "i" at time period " $\mathrm{t}$ ", $X_{i t}$ denotes GDP per capita in region "i" at time period " $\mathrm{t}^{\text {" }}$. $Z_{i t}$ stands for the other related variables. With regard to this model, (i) when $\beta_{2}=\beta_{3}=0$ and $\beta_{1}>0$, we can say there is a continuously increasing relationship between income per capita and pollution per capita. (ii) If $\beta_{1}<0, \beta_{2}>0$ ve $\beta_{3}=0$; the model will transform into quadratic form. In accordance with EKC hypothesis it can be granted an inverted $U$ shape relationship between per capita income and pollution per capita (Figure 1-A), (iii) finally in a cubic form model if $\beta_{1}>0$, $\beta_{2}<0$ ve $\beta_{3}>0$; we can talk about an $\mathrm{N}$-shaped relationship (Figure 1-B). Other possibilities concerning the significance of parameters are not within the scope of EKC literature.

\section{Figure 1: Quadratic and cubic functions for the estimation of the EKC Hypothesis}
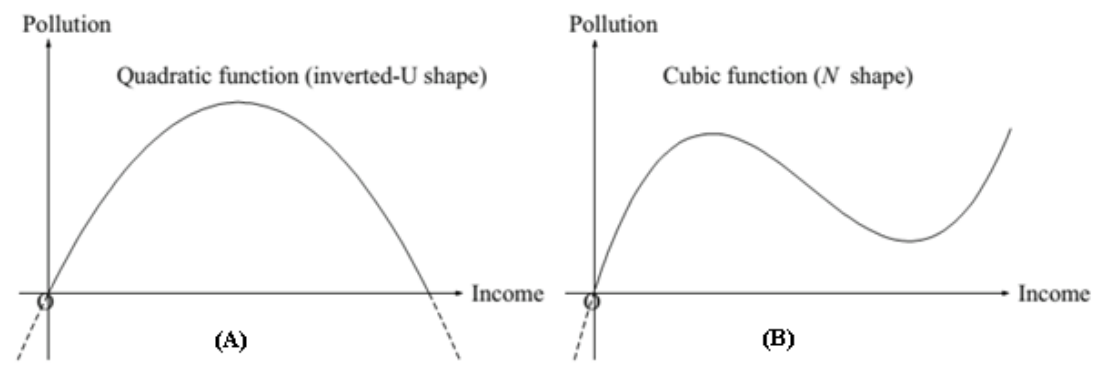

In the empirical EKC literature, presented the $\mathrm{N}$-shaped scenario, in which economic growth provides to environmental recovery initially, yet it generates more severe environmental degradation beyond a certain income level. (Panayotou, 1993; Moomaw and Unruh, 1997; Bryun and Opschoor, 1997, Akbostanci et al., 2009) Dasgupta et al. (2002) argued that the slope or form of the curve may take various shapes according to the type of pollutant and context of pollution. Although EKC hypothesis implies that doing nothing is the best policy because as income increases the pollution problem will be solved automatically, empirical studies offer very little support for the strong policy conclusion that economic growth alone is the solution to all environmental problems. The empirical studies on EKC Hypothesis can be grouped under three titles: cross-country studies (Grossman and Krueger, 1995; Shafik, 1994; Stern et al., 1996), time series analysis (Egli, 2002; Vincent, 1997) and panel data analysis (Dijkgraaf and Vollebergh 1998, 2001; de Bruyn et al., 1998; Wagner, 2008; Torras and Boyce, 1998; Panayotou et al., 2000).

\footnotetext{
${ }^{3}$ It has seen that according to the studies based on reduced model, the lagging indicators of per capita income are used. (Bradford et.al., 2005; Coondoo and Dinda, 2002; Grossman and Krueger, 1995; Perman and Stern, 2003).
} 
Our empirical analysis exploits a balanced panel of annual observations and covers 27 countries ${ }^{4}$, chosen on the basis of their development level and share in the total world CO2 emissions, over a 13-year period (1997-2009). 25 of the sample counties are in the high human development classification in the Human Development Index within the related time period. In addition, according to the Human Development Report 2007/2008, these countries are responsible from approximately $65 \%$ of the total $\mathrm{CO} 2$ emissions in the world. The dataset consists of 351 observations for each variable of the each panel. All the data was provided from the Worldbank Open Data (data.worldbank.org).

In our analysis, we focus on CO2emissions per capita (in metric tons), which are viewed to be the most important global pollutant contributing about $72 \%$ of the global warming effects. For the independent variables real GDP per capita at year 2005 constant prices was used. Moreover, patent applications of residents, research and development expenditures (as a percentage of GDP) and value added industrial production were adopted as additional independent variables. Patent applications and research and development expenditures were used as proxy of innovative activity. Value added industrial production (as a percentage of GDP) is added to the model because an important part of the $\mathrm{CO} 2$ emission is sourced by industrial production.

As it was explained before, the EKC hypothesis assumes that as income increases, public consciousness and eco-friendly behavior rises, and as technology advances, emission of pollutants per unit of production decreases. Therefore, it can be expected beyond a certain income level, environmental pollution is diminished. However some theoretical and empirical studies presented the $\mathrm{N}$-shaped scenario which proposes that increasing GDP per capita provides environmental recovery initially, but the level of environmental degradation is getting worse beyond a certain income level. Within this scope, hypothesis 1 and 2 of this study examine what kind of relationship exists between $\mathrm{CO} 2$ emission, and economic growth:

Hypothesis 1. Emission of $\mathrm{CO} 2$ will have a statistically significant relationship with GDP, showing an inverted U-shaped curve.

Hypothesis 2. Emission of $\mathrm{CO} 2$ will have a statistically significant relationship with GDP, showing an $\mathrm{N}$-shaped curve

Baltagi (2005) states that the fixed effects model (FEM) is an appropriate specification if the observations focus on a specific set of $\mathrm{N}$ firms, countries or states which are under similar conditions while the random effects model (REM) is an appropriate specification if the observations are drawn randomly from a large population. From this point of view FEM would be a better choice than the REM since we are interested in estimating the relationship between $\mathrm{CO} 2$ emissions, GDP per capita and innovation level for the predetermined selections of countries. We have checked these two alternative specifications using the Hausman test, and the choice of the FEM is supported by the data.

\footnotetext{
${ }^{4}$ Austria, Belgium, Bulgaria, Canada, China, Czech Republic, Denmark, Finland, France, Germany, Hungary, Japan, Republic of Korea, Lithuania, Mexico, Netherlands, Poland, Portugal, Romania, Russian Federation, Singapore, Slovak Republic, Slovenia, Spain, Turkey, United Kingdom, United States.
} 
In order to investigate the most appropriate model of EKC between the inverted U-shaped scenario and the $\mathrm{N}$-shaped scenario, this study puts forward two specifications for the emission of $\mathrm{CO} 2$ per capita as follows:

Model 1. $C O 2_{i t}=\beta_{0}+\beta_{1} G D P_{i t}+\beta_{2} G D P_{i t}^{2}+\beta_{4}$ patent $_{i t}+\beta_{5} r \& d_{i t}+\beta_{6}$ industry $_{i t}+$ $\mu_{i}+u_{i t}$

Model 2. $C O 2_{i t}=\beta_{0}+\beta_{1} G D P_{i t}+\beta_{2} G D P_{i t}^{2}+\beta_{3} G D P_{i t}^{3}+\beta_{4}$ patent $_{i t}+\beta_{5} r \& d_{i t}+$ $\beta_{6}$ industry $_{i t}+\mu_{i}+u_{i t}$

where $\mathrm{i}$ represents the countries and $\mathrm{t}$ is the year, $\mathrm{CO} 2_{i t}$ denotes $\mathrm{CO} 2$ emission per capita, GDP $P_{i t}$ denotes GDP per capita (constant 2005 USD), patent it $_{\text {it }}$ is the patent applications of the residents, $r \& d_{i t}$ is the research and development expenditures as a percentage of GDP, industry $_{i t}$ is the value added industrial production as a percentage of GDP. $\beta_{0}$ stands for the specific country-pair effects and allows to control for all omitted variables that are cross-sectionally specific but remain constant over time. $\mu_{i}$ denotes the unobservable country-specific effect and $u_{i t}$ denotes the remainder disturbance.

For Model 1, if significant parameters satisfy $\beta_{1}>0$ and $\beta_{2}<0$, then an inverted-U relationship exist. For Model 2, if significant parameters satisfy $\beta_{1}>0$ and $\beta_{2}<0$ and $\beta_{3}>0$, then there exist an $\mathrm{N}$-shaped relationship. For both models expected value for $\beta_{4}$ and $\beta_{5}$ are negative due to the positive effect of innovative investments on clean environment. Expected value of $\beta_{6}$ is positive because industial production is assumed as one of the main components of the $\mathrm{CO} 2$ emissions.

\section{EMPIRICAL RESULTS}

The results of descriptive statistics on variables are summarized in Table 1 . The number of valid observations is 351, and the average emission volume of $\mathrm{CO} 2$ is 8.59 tons.

Table1: Descriptive Statistics

\begin{tabular}{lrrrr}
\hline Variable & Min & Max & Mean & Std. Dev. \\
\hline CO2 (metric tons per capita) & 2.65 & 20.25 & 8.59 & 3.79 \\
GDP per capita (constant 2005 USD) & 916.20 & 49554.91 & 21429.86 & 14034.94 \\
Patent Applications of Residents & 62.00 & 384201.00 & 31283.46 & 77138.78 \\
R\&D Expenditures (\% of GDP) & 0.34 & 3.93 & 1.57 & 0.90 \\
Industry (\% of GDP) & 19.06 & 47.95 & 30.79 & 5.57 \\
\hline
\end{tabular}

The model is tested for heteroskedasticity, cross-sectional dependence and serial correlation. Modified Wald test represented the existence of heteroskedasticity. Pesaran, Friedman and Frees tests proved the cross-sectional dependence in the panel. 
Both Baltagi-Wu local best invariant (LBI) test and Durbin-Watson test indicated the existence of serial correlation. The results given in the Table 1 are the robust coefficients that are adjusted by Driscoll-Kraay estimator.

Table2: Panel-data Regression Results

\begin{tabular}{|c|c|c|c|c|}
\hline$G D P_{i t}$ & 0.0000645 & $(-0.0000357)$ & $0.000229 *$ & (8.11E-05) \\
\hline$G D P_{i t}^{2}$ & $-2.14 \mathrm{E}-09 *$ & $(3.78 \mathrm{E}-10)$ & $-1.08 \mathrm{E}-08^{*}$ & (3.72E-09) \\
\hline$G D P_{i t}^{3}$ & - & - & $1.16 \mathrm{E}-13^{* *}$ & $(4.78 \mathrm{E}-14)$ \\
\hline patent $_{i t}$ & $0.0000135 *$ & $(1.38 \mathrm{E}-06)$ & $1.25 \mathrm{E}-05^{*}$ & (1.50E-06) \\
\hline$r \& d_{i t}$ & $-0.4752772 * *$ & $(0.1926033)$ & $-0.425550 * *$ & $(0.200446)$ \\
\hline industry $_{i t}$ & $0.1011806 *$ & $(0.0342938)$ & $0.091599 *$ & $(0.030564)$ \\
\hline \multirow[t]{4}{*}{ Constant } & $5.7863530 *$ & $(1.2024000)$ & $5.556494^{*}$ & (1.180927) \\
\hline & $R^{2}$ & 0.1924 & $R^{2}$ & 0.201 \\
\hline & $F(5,26)$ & 355.58 & $F(6,26)$ & 619.45 \\
\hline & Prob $>F$ & 0 & Prob $>F$ & 0 \\
\hline
\end{tabular}

Note: Robust standard errors are represented in parentheses. Coefficients with $\left({ }^{*}\right)$ are significant at $1 \% ;\left({ }^{*}\right)$ are significant at $5 \%$. Coefficients in bold are not significant at standard levels.

Both the Model 1 and 2 of the fixed effects model are found significant by F-test. Signs of coefficients for GDP variables are just as expected before and $\mathrm{R}^{2}$ values are quite similar for both models. However in Model $1 \beta_{1}$ is found insignificant for standard levels. Thus, for $\mathrm{CO} 2$ emissions, Model 2 reports of the existence of an $\mathrm{N}$-shaped EKC represented by GDP per capita. The turning points of the estimated model are calculated as \$13575 and $\$ 48493$. Therefore, we can say that in the selected countries that have per capita GDP approximately less than $\$ 13575, \mathrm{CO} 2$ emissions tends to increase as GDP per capita increases. However, for the selected countries those have per capita incomes ranging approximately between $\$ 13575$ and $\$ 48493 \mathrm{CO} 2$ emissions decline. It can be argued that, through the development process as per capita GDP of selected countries increase beyond $\$ 48493$ level, CO2 emissions is expected to rise once again. 
On the other hand, Model 2 reports that research and development expenditures is negatively associated with emissions of $\mathrm{CO} 2$, while patent applications and industrial production are positively related to $\mathrm{CO} 2$ emissions. We have chosen research and development expenditures and patent applications as proxy of innovative investments. Research and development expenditures are negatively related to the $\mathrm{CO} 2$ emissions as it is expected. Surprisingly, our model put forwards that patent applications have a positive significant relationship with $\mathrm{CO} 2$ emissions. However it must be emphasized that the coefficient of patent applications $\left(\beta_{4}\right)$ is minor in comparison with the other control variables. This unexpected result can be explained by the nature of the patent data that is used in the model. The available data contains all the patent applications of the residents, not only environmental patents. Additionally $\mathrm{CO} 2$ emissions rises along with the growth in the industrial production which coincide with the common sense that industrial activity are one of the major contributors to $\mathrm{CO} 2$ emission.

\section{CONCLUSION}

In order to investigate the relationship between per capita GDP and CO2 emissions, this study examined an EKC hypothesis empirically as it applied to 27 developed countries from 1997 through 2009. Moreover, it is attempted to test the existence of various scenarios related to the shape of EKC and analyzed the impact of innovative investments and industrial production which is recognized to be one of the main causes of the greenhouse gas emissions.

According to our empirical results, we assert that there is an $\mathrm{N}$-shaped relationship between per capita GDP and CO2 with the turning points $\$ 13575$ and $\$ 48493$ respectively. The finding of $\mathrm{N}$-shaped relationship for $\mathrm{CO} 2$ emissions and GDP per capita in our analysis implies that the EKC hypothesis is not supported by this data set. EKC hypothesis implies that persistent development is the best policy because as income increases the level of pollution will decrease eventually. Nevertheless some economists state that EKC is the argument of the mainstream economists who defend growth through more liberalized world markets. Therefore, one of the most important conclusions of our study is that actions against the environmental problems cannot wait until per capita GDP rise. Findings of this study represents that $\mathrm{CO} 2$ emissions will not disappear automatically with economic growth, on the contrary it can be more severe after a certain level of GDP per capita.

On the other hand, it is found that research and development expenditures and industrial production are the other significant variables in explaining $\mathrm{CO} 2$ emissions. As consistent with the ongoing literature, innovation influences $\mathrm{CO} 2$ emissions directly and indirectly given its close relationship with income. In addition, based on the positive significant relationship between industrial production and $\mathrm{CO} 2$ emissions, more eco-friendly industrial process should be encouraged. 


\section{REFERENCES}

- Akbostanci, E. - S. Turut-Asik and G. I. Tunc (2009), "The Relationship between Income and Environment in Turkey: Is There an Environmental Kuznets Curve?", Energy Policy, 37 (3), pp. 861-867

- $\quad$ Ayres, R. U. and J. Van den Bergh (2005), "A Theory of Economic Growth with Material/Energy Resources and Dematerialization: Interaction of Three Growth Mechanisms", Ecological Economics, 55(1), pp. 96-118.

- Baiardi, D. (2014), "Technological Progress and the Environmental Kuznets Curve in the Twenty Regions of Italy", The B. E. Journal of Economic Analysis and Policy, 14(4), pp. 1501-1542.

- Baltagi, B. H. (2005), Econometric Analysis of Panel Data, 3rd ed., John Wiley and Sons.

- Beckerman, W. (1992), "Economic Growth and the Environment: Whose Growth? Whose Environment", World Development, 20, pp. 481-496.

- Bhattarai, M. and M Hammig (2001), "Institutions and the Environmental Kuznets Curve for Deforestation: A Cross-Country Analysis for Latin America, Africa, and Asia", World Development, 29(6), pp. 995 - 1010.

- Bradford D. F. - R. A. Fender - S. H. Shore and M. Wagner (2005), "The Environmental Kuznets Curve: Exploring a Fresh Specification", The B. E. Journal of Economic Analysis and Policy, 4(1).

- Bruyn, S. M. and J. B. Opschoor (1997), "Development in the Throughput-Income Relationship: Theoretical and Empirical Observation", Ecological Economics, 20(3), pp. 255-268.

- Carson, R.T. - Y. Jeon and D. R. McCubbin (1997), "The Relationship between Air Pollution Emissions and Income: US Data", Environment and Development Economics, 2(4), pp. 433-450.

- Coondoo, D. and S. Dinda (2002), "Causality between Income and Emission: A Country Group-Specific Econometric Analysis", Ecological Economics, 40(3), pp. 351-367.

- Dasgupta, S. - B. Laplante - H. Wang and D. Wheeler (2002), "Confronting the Environmental Kuznets Curve", The Journal of Economic Perspectives, 16(1), pp. 147-168

- Dasgupta, S. - K. Hamilton - K. D. Pandey and D. Wheeler (2006), "Environment During Growth: Accounting for Governance and Vulnerability", World Development, 34(9), pp. 1597-1611.

- De Bruyn, S.M. - J. C. J. M. Van Den Bergh and J. B. Opschoor (1998), "Economic Growth and Emissions: Reconsidering the Empirical Basis of Environmental Kuznets Curves", Ecological Economics, 25(2), pp. $161-175$

- Dijkgraaf, E. and H. R. S. Vollebergh (1998), "Growth and Environment-Is There a Kuznets Curve for Carbon Emissions?", $2^{\text {nd }}$ ESEE conference, University of Geneva. 
- Dijkgraaf, E. and H. R. S. Vollebergh (2001), “A Note on Testing for Environmental Kuznets Curves with Panel Data", FEEM Working Paper, No: 63.

- Egli, H. (2002), "Are Cross-Country Studies of the Environmental Kuznets Curve Misleading? New Evidence From Time Series Data or Germany", FEEM Working Paper, No: 25.

- Grossman, G.M. and A. B. Kruger (1991), "Environmental Impacts of the North American Free Trade Agreement", NBER Working Paper, No: 3914.

- Grossman, G.M. and A.B. Krueger (1995), "Economic Growth and the Environment", Quarterly Journal of Economics, 110 (2), pp. 353-377.

- Halicioglu, F. (2009), “An Econometric Study of CO2emissions, Energy Consumption, Income and Foreign Trade in Turkey", Energy Policy, 37(3), pp. 1156-1164.

- He, Y. W and J. R. Jiang (2012), "Technology Innovation Based on Environmental Kuznets Curve Hypothesis", Advance Material Research, 573-574, pp. 831-835.

- Huang, D. R (2011), "Study on the Internal Relationship between Porter Hypothesis and Environmental Kuznets Curve", Science and Technology Information, 27.

- Kuznets, S. (1955), "Economic Growth and Income Inequality", American Economic Review, 45 (1), pp. 1-28.

- Lantz, V. and Q. Feng (2006), “Assessing Income, Population, and Technology Impacts On CO2 Emissions in Canada: Where's The EKC?", Ecological Economics, 57(2), pp. 229-238.

- Meadows, D. H. - D. L. Meadows - J. Randers and W.W. Behrens (1972), The Limits to Growth, New York University Books.

- Moomaw, W. R. and G. C. Unruh (1997), "Are Environmental Kuznets Curves Misleading Us? The Case of CO2emissions", Environment and Development Economics, 2(4), pp. 451-463.

- Panayotou, T. (1993), "Empirical Tests and Policy Analysis of Environmental Degradation at Different Stages of Economic Development", ILO Technology and Employment Program Working Paper, No: WP238.

- Panayotou, T. - A. Peterson and J. Sachs (2000), "Is the Environmental Kuznets Curve Driven by Structural Change? What Extended Time Series May Imply for Developing Countries?", CAER II Discussion Paper, No:80.

- Perman, R. and D. I. Stern (2003), "Evidence from Panel Unit Root and Cointegration Tests that the Environmental Kuznets Curve Does Not Exist", Australian Journal of Agricultural and Resource Economics, 47(3), pp. 325-347.

- Porter, M. E. and van der Linde, C., (1995), "Toward a New Conception of the Environment-Competitiveness Relationship", Journal of Economic Perspectives, 9 (4), pp. 97-118. 
- $\quad$ Selden, T.M. and D. Song (1994), "Environmental Quality And Development: Is There A Kuznets Curve for Air Pollution Emissions?", Journal of Environmental Economics and Management, 27 (2), pp. 147-162.

- Shafik, N. and S. Bandyopadhyay (1992), "Economic Growth and Environmental Quality: Time Series and Cross-Country Evidence", Background Paper for World Development Report 1992, World Bank, Washington DC.

- Shafik, N. (1994), "Economic Development and Environmental Quality: An Econometric Analysis", Oxford Economic Papers, 46, pp. 757 - 773.

- Stern, D.I. - M. S Common and E. B. Barbier (1996), "Economic Growth and Environmental Degradation: The Environmental Kuznets Curve and Sustainable Development", World Development, 24(7), pp. 1151-1160.

- Torras, M. and J. K. Boyce (1998), "Income, Inequality, and Pollution: A Reassessment of the Environmental Kuznets Curve", Ecological Economics, 25(2), pp. $147-160$.

- Wagner, M., and G. Müller-Fürstenberger (2008), "The Carbon Kuznets Curve: $A$ Cloudy Picture Emitted by Bad Econometrics?", Resource and Energy Economics, 30(3), pp. 388-408.

- Vincent, J.R. (1997), "Testing for Environmental Kuznets Curves within a Developing Country", Environment and Development Economics, 2(4), pp. 417 431. 